\title{
A hierarchy of determining factors controls motoneuron innervation
}

\section{Experimental studies on the development of the plantaris muscle (PL) in avian chimeras*}

\author{
M. Grim ${ }^{1}$, K. Nensa ${ }^{2}$, B. Christ ${ }^{2}$, H.J. Jacob ${ }^{2}$, and K.W. Tosney ${ }^{3}$ \\ ${ }^{1}$ Department of Anatomy, Charles-University Prague, U nemocnice 3, CS-12800 Prague 2, Czechoslovakia \\ 2 Department of Developmental Biology, Institute of Anatomy, Ruhr-University Bochum, \\ Universitätsstrasse 150, D-4630 Bochum 1, Federal Republic of Germany \\ ${ }^{3}$ Department of Biology, University of Michigan, Ann Arbor, MI 48109, USA
}

Summary. Quail leg buds were grafted in place of chick leg buds or chick wing buds and vice versa at stages 18 to 21 after colonization by muscle precursor cells had been completed. Motor endplate pattern in the plantaris muscle of the grafts was analyzed before hatching by means of esterase and acetylcholinesterase staining techniques. Muscle fibre types were made visual using the myosin ATPase reaction. Investigations are based on the species-specific endplate pattern of the plantaris muscle: multiply innervated fibres in the chick and focally innervated fibres in the quail. Muscle pieces isolated from the adjacent medial gastrocnemius muscle of the grafted legs were histologically examined to judge their species-specific composition. Horseradish peroxidase was injected into the plantaris muscles of both the grafted and the opposite leg as well as in the plantaris muscle of normal quail embryos, in order to be sure that the plantaris muscle of the graft is innervated by appropriate motoneurons. This procedural design offers for the first time a possibility to test experimentally the influences of motoneurons on endplate pattern formation under conditions corresponding to those in normal ontogenesis. It is shown that such appropriate motoneurons of one species which project to the plantaris muscle of the other species dictate the endplate pattern. When the plantaris muscle is innervated by inappropriate motoneurons, the endplate pattern inherent in the muscle primordium itself becomes realized. A sequence of hierarchically acting factors is proposed to bring different results in line. According to this, the neuronally set programme has priority compared with that set in the muscle. This is true for the normal development and might generate the high neuro-muscular specificity. If under experimental conditions the neuronal programme and the peripheral programme differ, the axons and muscle fibres selectively interact with respect to their inherent characteristics and the muscle-specific programme becomes expressed. If there is a lack of a certain axon type,

\footnotetext{
* The authors wish to thank the DAAD and the Ceskolovenská Lékarská Spolecnost J.E. Purkyné for sponsorship. This work was supported in part by NIH grants to Bruce M. Carlson and to Kathryn Tosney

Abbreviations: $P L$, plantaris muscle; $P L D$, posterior latissimus dorsi muscle; $A L D$, anterior latissimus dorsi muscle; $U M D$, ulnimetacarpalis dorsalis muscle; $E$, days of embryonic development; $H R P$, horseradish peroxidase; $L M C$, lateral motor column; $L S$, lumbosacral
}

Offprint requests to: $\mathrm{B}$. Christ muscle fibres might become innervated by non-corresponding motoneurons which alter the muscle fibre type.

Key words: Muscle innervation - Endplate pattern formation - Hierarchy of controlling factors - Muscle fibre types - Plantaris muscle - Quail-chick chimeras

\section{Introduction}

Limb muscles of birds are found to be made up of focally innervated fibres, multiply innervated fibres, and a mixture of both types (Ginsborg 1960; Hess 1961; Barnard et al. 1982). The posterior latissimus dorsi muscle (PLD), for example, is composed of focally innervated fibres that are known to contract fast. The anterior latissimus dorsi muscle (ALD), on the other hand, contains multiply innervated fibres which are slow. Most of the limb muscles are formed by focally innervated fibres. Besides the ALD, the dorsal part of the ulnimetacarpalis dorsalis muscle (UMD) is formed by multiply innervated fibres whereas the ventral part of this muscle is focally innervated (Grim et al. 1983). Another well known chick muscle exhibiting mainly multiply innervated fibres is the adductor profundus muscle (Barnard et al. 1982).

The innervation type of the plantaris muscle (PL) has recently been studied in detail (Grim et al. 1985). Continuing former observations of Melichna et al. (1974) who found the PL to be mainly multiply innervated, Grim et al. compared the innervation types of the chick PL and the quail PL. They discovered that, unlike the multiply innervated chicken PL, the PL of the quail shows only one or two bands of endplates on the surface. The majority of isolated muscle fibres is found to be focally innervated by "en plaque" endplates. On the basis of this species-specific endplate pattern the PL can be used as a model suited to study the motoneuron-muscle interactions in developing chimeras.

Regarding the development of functional motor endplates several steps can be distinguished. It is widely accepted that axons growth on stereotyped highways into the limb bud and the relation between motoneurons and muscle cells display a high specificity (Hollyday 1980; Landmesser 1980). According to the concept of motoneuron-muscle specifity, motoneurons are initially determined with respect to their peripheral destination (Landmesser and Morris 1975). On the other hand, experimental studies have given 
evidence that also a mismatch can occur of motoneurons are forced to innervate a foreign muscle (Bennett and Pettigrew 1974; Jacob et al. 1983; Jirmanová and Zelená 1973).

Where are the factors situated which determine the endplate pattern of limb muscles? At first glance, there appear to be two possibilities: the motoneurons determine the synaptic pattern and fibre type distribution, or the developing muscle itself controls this process. Observations exist that support both points of view. On the one hand, heterotopically replacements of pieces of the neural tube, for instance, as were done by Khaskiye et al. (1980), seem to prove the hypothesis favouring the determining influence of motorneurons. On the other hand, Jacob et al. (1983) have shown that an UMD inappropriately innervated does not change its normal endplate pattern. Additionally, Butler et al. (1982), as well as Phillips and Bennett (1984), show the initial differentiation of distinct fibre types analyzed by myosin-ATPase profiles appears normally even in aneurogenic limbs.

Since it is common to most of the experimental approaches being aimed at this problem that muscles are always forced to interact with inappropriate motoneurons, the question remains whether the results obtained are true for normal neuro-muscular interactions occuring during normal ontogenesis. The species-specific differences of the endplate pattern in the PL of chick and quail thus represent a favourable model to study interactions between muscle fibres and neurons of corresponding characteristics.

In this paper we focus on the PL in quail-chick chimeras addressing special attention to the formation of endplate pattern of PL muscles in the quail leg connected with appropriate or inappropriate motoneurons of the chick spinal cord and vice versa. Therefore leg buds of one species have been grafted in the place of leg or wing buds of the other species. A hierarchy of controlling factors is proposed which come from motoneurons as well as muscle primordia.

\section{Materials and methods}

Eggs of White Leghorn chick (Gallus domesticus) and of Japanese quail (Coturnix coturnix japonica) were incubated at $38^{\circ} \mathrm{C}$ and $80 \%$ humidity. Young embryos were staged according to the criteria of Hamburger and Hamilton (1951) ("HH-stages"), older embryos corresponding to the total period of incubation (e.g. E $18=18$ days). After opening of the egg containing the host, the embryo was floated up to the level of the shell window by dripping Locke solution (Hara 1971). For microsurgical procedures iridectomy scissors and electrolytically sharpened tungsten needles (Dossel 1958) were used.

In a first series of experiments leg buds of quail embryos (HH-stages 18 to 21) were isolated and grafted in place of chick leg buds previously removed from embryos at corresponding stages. Grafts were fixed by the tension of the clipped amnion. In a second series of experiments quail leg buds were replaced by chick leg buds. Host and donor embryos ranged from $\mathrm{HH}$-stages 18 to 21 . In a third experimental series chick (or quail) leg buds were heterotopically transplanted in place of quail (or chick) wing buds. In these cases leg buds were temporarily fixed by means of cactus needles. The migration of somite-derived muscle precursor cells into the leg bud had been completed by the time of grafting (Jacob et al. 1979). Stages of embryos correspond to that used in the other series. E 16 to E 20 chick hosts

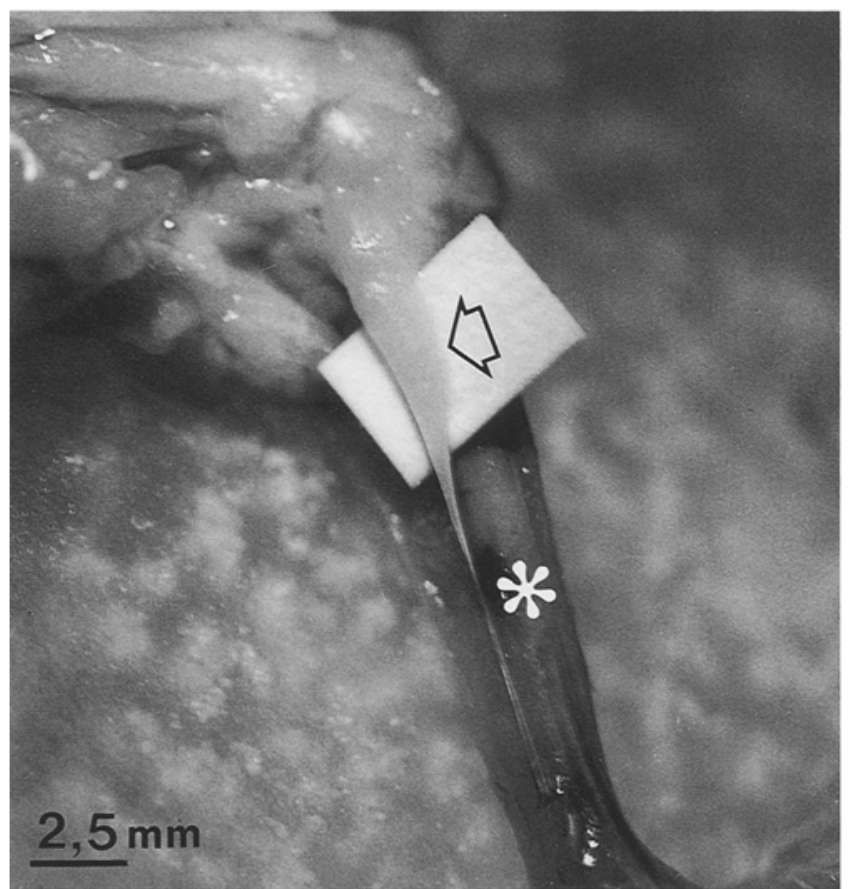

Fig. 1. Sectioned PL muscle of a 20-day chick embryo. Arrow: muscle belly; asterisk: tibia. Note the long tendon of the muscle

and $\mathrm{E} 15$ or $\mathrm{E} 16$ quail hosts were fixed respectively in $4 \%$ neutral formaldehyde and Serra's fluid. A total of 557 grafting experiments was performed and 96 embryos were evaluated. Only normally developed legs were used for evaluation. Limbs were skinned and a piece of muscle tissue from the proximal part of the medial gastrocnemius muscle, bordering on the PL, was used for histological examination. After microdissection the PL was fixed in situ for approximately $15 \mathrm{~min}$. The isolated PL was further fixed for a total period of 1 to several hours. After washing in water the whole muscle was incubated at $37^{\circ} \mathrm{C}$ according to the indigogenic method of Holt (1958), as modified by Lojda et al. (1979), for demonstration of motor endplates. For comparison of endplate pattern the PL of the contralateral leg was treated in the same manner. In some cases endplates were demonstrated in teased small bundles of muscle fibres using the method of Karnovsky and Roots (1964). According to Barnard et al. (1982), and Grim et al. (1985), the chick PL is made up only by multiply innervated fibres. Therefore, the following criteria for classification of quail PL were used: 1. location of "en plaque" endplates at the dorsal PL surface in a limited zone, 2. fibres of a teased small bundles exhibiting only one endplate over a long distance (minimum: $2 \mathrm{~mm}$ ).

$\mathrm{PL}$ and medial gastrocnemius muscle have the same origin. To make sure that the PL is formed by donor cells a piece of the adjacent gastrocnemius muscle was stained according to the method of Feulgen and Rossenbeck (1924). As the interphase nuclei of Japanese quail cells are characterized by a large mass of nucleolus-associated heterochromatin DNA which does not exist in the chick nuclei, quail cells can be distinguished from chick cells (Le Douarin 1969).

The qualified statement of Tanaka and Landmesser (1986) which concerns difficulties of distinction between quail and chick nuclei at late embryonic stages is not very 

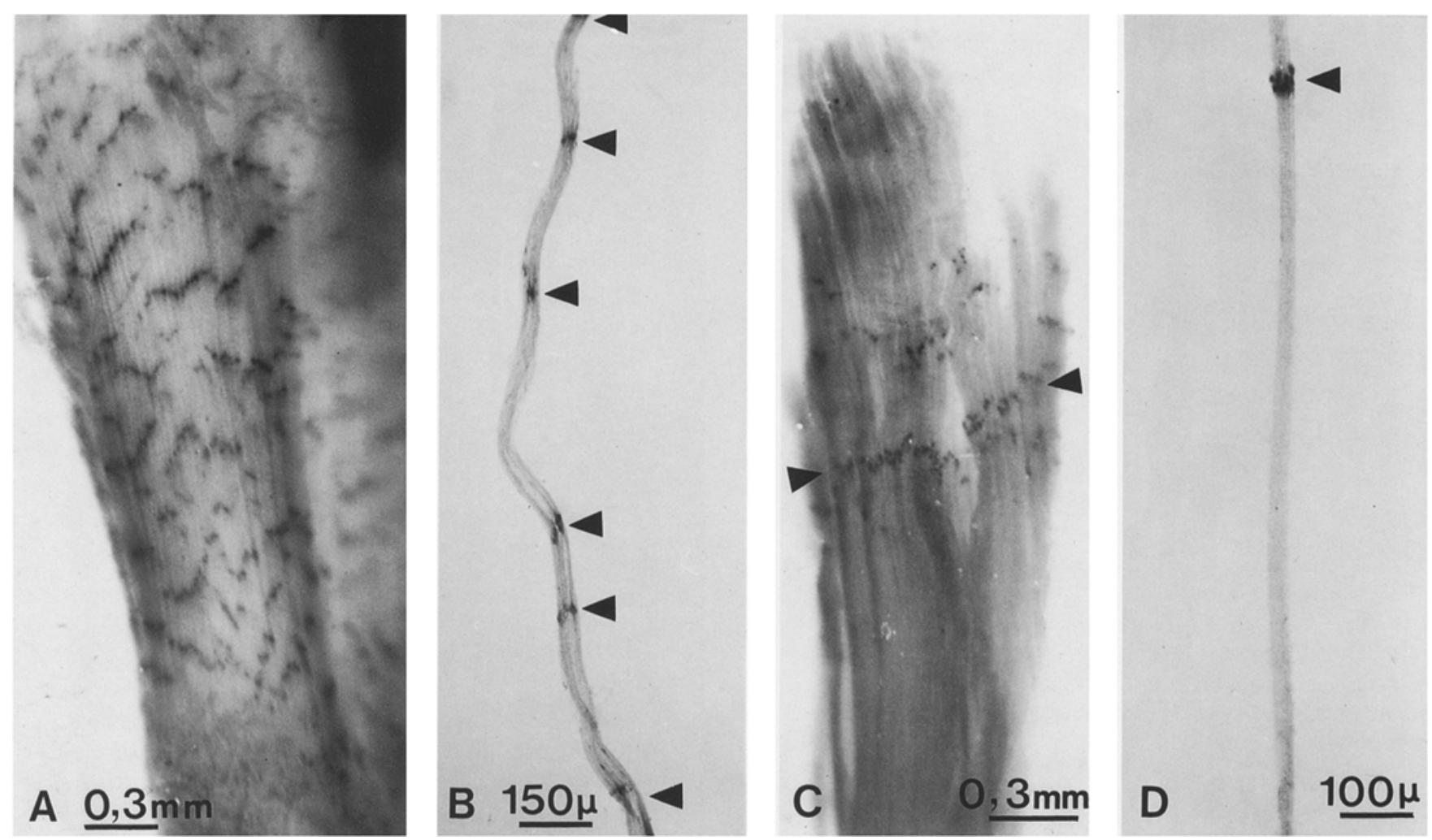

Fig. 2 A-D. Normal PL muscles and muscle fibre bundles of chick and quail cut out from prehatching embryos. A Dorsal surface of a chick PL. Endplates are stained according to the indigogenic method. B Small bundle of a chick PL stained for acetylcholinesterase. Note the multiple innervation. C Dorsal surface of a quail PL. D Small bundle of a quail PL. Note the focal innervation. Arrows: endplates

well founded. Jacob et al. (1986) have shown that in muscles of chimeras 2 weeks after hatching nuclei can easily be distinguished. This seems to be a problem of fixation.

Fibre type composition of quail PL, chick PL and PL of chimeras was visualized using myosin ATPase reaction. Muscles were frozen in Freon cooled by liquid nitrogen. Unfixed cryostat sections $(10 \mu \mathrm{m})$ were used for detection of myosin ATPase by the calcium-cobalt method of Padykula and Herman (1955) as modified by Lojda et al. (1979). Some sections were preincubated for $15 \mathrm{~min}$ by $20^{\circ} \mathrm{C}$ using potassium acetate buffer $\mathrm{pH} 4.3$ according to Guth and Samaha (1970).

To prove that the PL in the grafted leg is appropriately innervated, the HRP method was used to demonstrate the motoneuron pool. E 10 and E 11 chick hosts were decapitated, eviscerated and skinned. The caudal body part was placed in Tyrode solution and PL of both legs was visualized by removing the medial part of the gastrocnemius muscle. HRP was injected through a glass pipette into the PL muscles of both the grafted and the opposite leg. In the same way, PL muscles of normal quail embryos (E 9 and $\mathrm{E} 10)$ were injected. Embryos were transferred into oxygenated Tyrode solution. Lumbosacral spinal cord was bared by removing the vertebral bodies. Specimens were incubated for $6 \mathrm{~h}$ at $32^{\circ} \mathrm{C}$, fixed in glutaraldehyde for $1 \mathrm{~h}$, washed for 6 days in TRIS-buffer changed several times and processed with diaminobenzidine (DAB) for development of the label. See for details of this procedure Landmesser (1978) as well as Tosney and Landmesser (1986).
Specimens were dehydrated, embedded in paraffin, and transversally sectioned. The sections were counter-stained with cresyl violet.

\section{Results}

\section{General}

A normal chick PL prepared by sectioning can be seen in Fig. 1. Figure 2 shows the chicken PL and the quail PL which can be distinguished by species-specific patterns of motor endplates. While the chicken PL is multiply innervated the quail $\mathrm{PL}$ is focally innervated. The experimental procedures performed are based on the purpose of getting connections between the PL of one species with motoneurons of the other species. If a leg bud of one species is grafted in place of a leg bud of the other species motoneurons are allowed to find an appropriate target, as the scheme shown in Fig. 3 exemplary demonstrates. Results of these experiments are described in the first and second parts of this chapter. In the third part results are described which were obtained after replacement of wing by leg buds. According to the latter procedural design inappropriate motoneurons are forced to innervate the PL. Finally, the pools of motoneurons innervating the PL in normal and grafted legs are described.

I. Quail PL innervated by appropriate motoneurons of the chick 


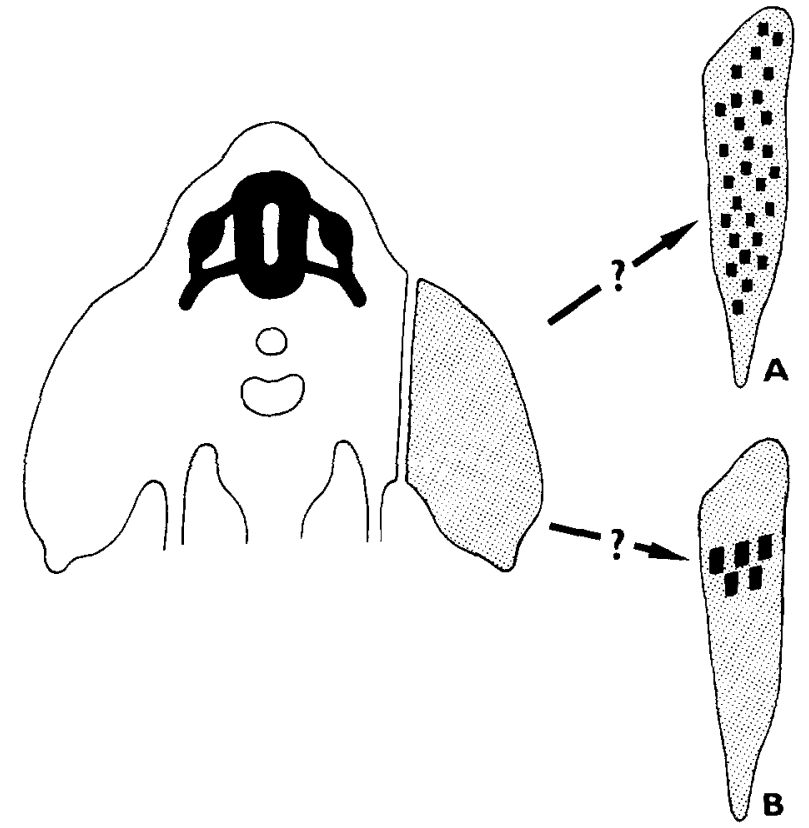

Fig. 3. Schematic representation of experimental procedures. Leg buds of one species are grafted instead of leg (or wing) buds in the other species. The question is whether the endplates of the PL innervated by motoneurons of the host neural tube develop in a chick-typical $(A)$ or in a quail-typical $(B)$ pattern. In the case illustrated, a quail leg bud (grey) is grafted in place of the right leg bud of a chick host (white). Black: neural tube spinal nerves and endplates of $\mathrm{PL}$

After grafting a quail leg bud instead of the chicken leg bud, in about $15 \%$ of the cases, a normally shaped quail leg was observed. Compared with the chick host leg of the contralateral side, its size is found to be in accordance with a normal quail leg at the corresponding developmental stage (Fig. 4). Depending on the age of the donor embryo at the time of grafting a more or less distinct feather pigmentation of quail characteristic can be seen. The skeletal and muscular pattern does not considerably differ from a normal quail leg.

The experimental design is based on condition that motoneurons of chick origin match muscle fibres of quail origin. To be sure about that, muscles of the grafts were histologically examined. Figure 5 shows an isolated piece cut out of the medial gastrocnemius muscle immediately covering the PL. The muscle fibres contain quail nuclei. Figure 6 shows the endplate pattern of quail PL innervated by appropriate chicken motoneurons. In more than $90 \%$ of evaluated specimen the endplate pattern is chick-typical, that is to say, the chick motoneurons must have determined and therefore "changed" the innervation type of the quail PL.

II. Chicken PL innervated by appropriate motoneurons of the quail

Results of this experimental series are similar to those obtained in the first one. Figure 7 shows a chick graft grown in place of a quail leg. While the quail host reveals pigmented feathers, the transplanted chick leg, for the most part, does not show pigmentation. It is worth mentioning that the transplanted leg of chick origin is often larger than

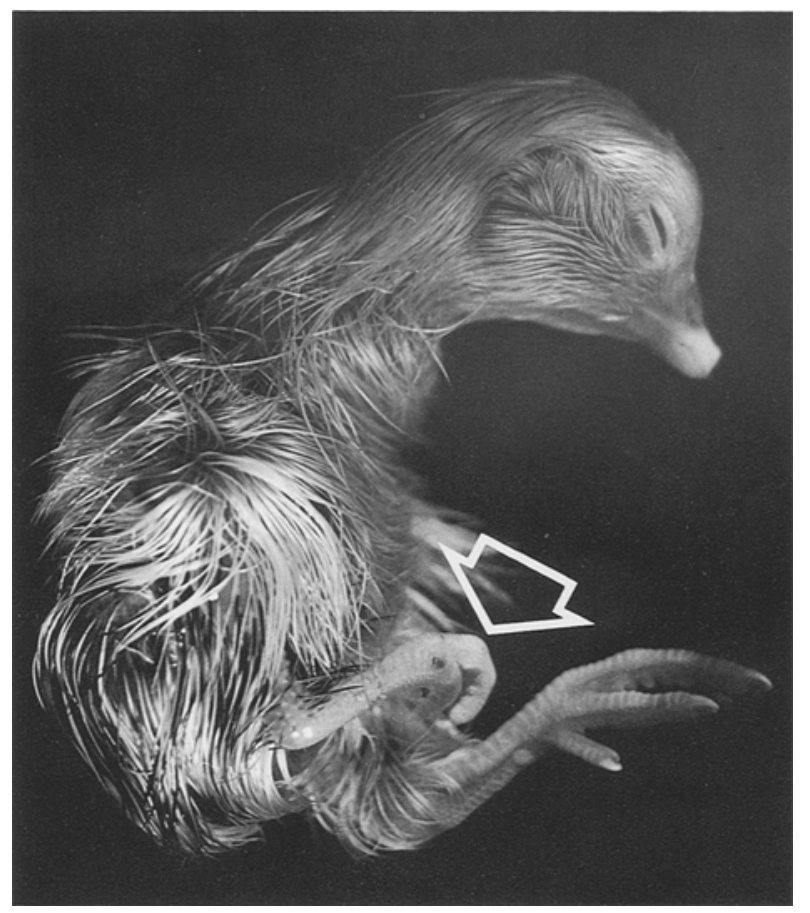

Fig. 4. Chick host after grafting a quail leg (arrow) in place of the right chick leg and a subsequent reincubation period of 17 days

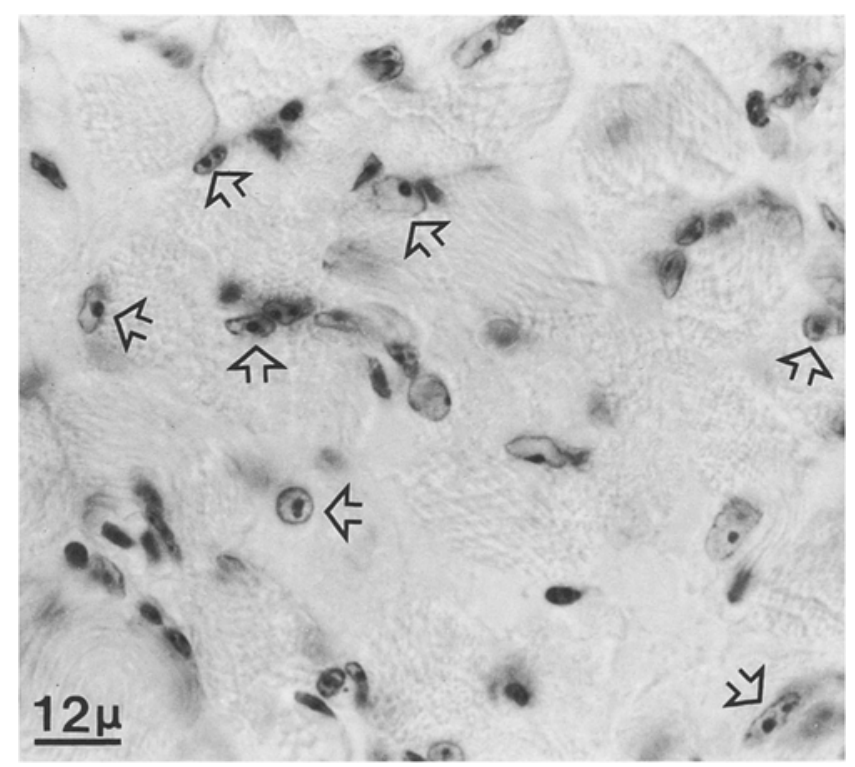

Fig. 5. Medial gastrocnemius muscle cut out from a grafted leg. Arrows: quail nuclei. Feulgen-staining

the normal quail leg at the contralateral side. Only PL muscles of those legs have been evaluated whose shape as well as skeletal and muscular pattern corresponded to normal legs. As was described above, in this series, too, histological examinations were performed in order to assure the chicken origin of muscle fibres (Fig. 8). Figure 9 shows the dorsal surface and a fibre bundle of such a chicken PL innervated by appropriate quail motoneurons. Most experiments performed in this series yield PL muscles of chick origin which reveal a quail typical motor endplate pattern. 

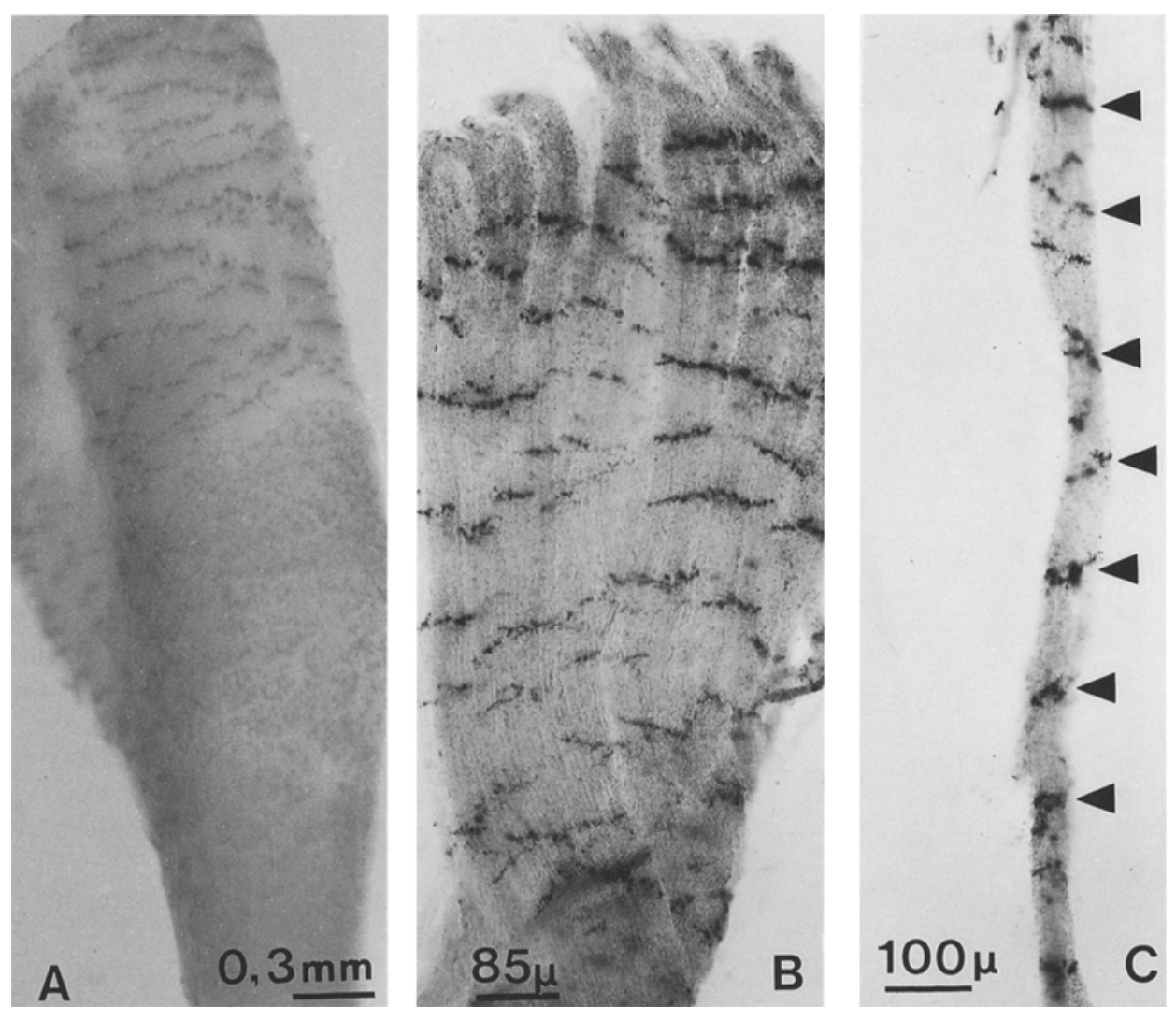

Fig. 6A-C. Chick-like endplate pattern of a quail PL in a quail leg grown in place of the chick leg. A Dorsal surface of the whole muscle.

B Dorsal part of the PL.

C Muscle fibre bundle. Arrows: endplates
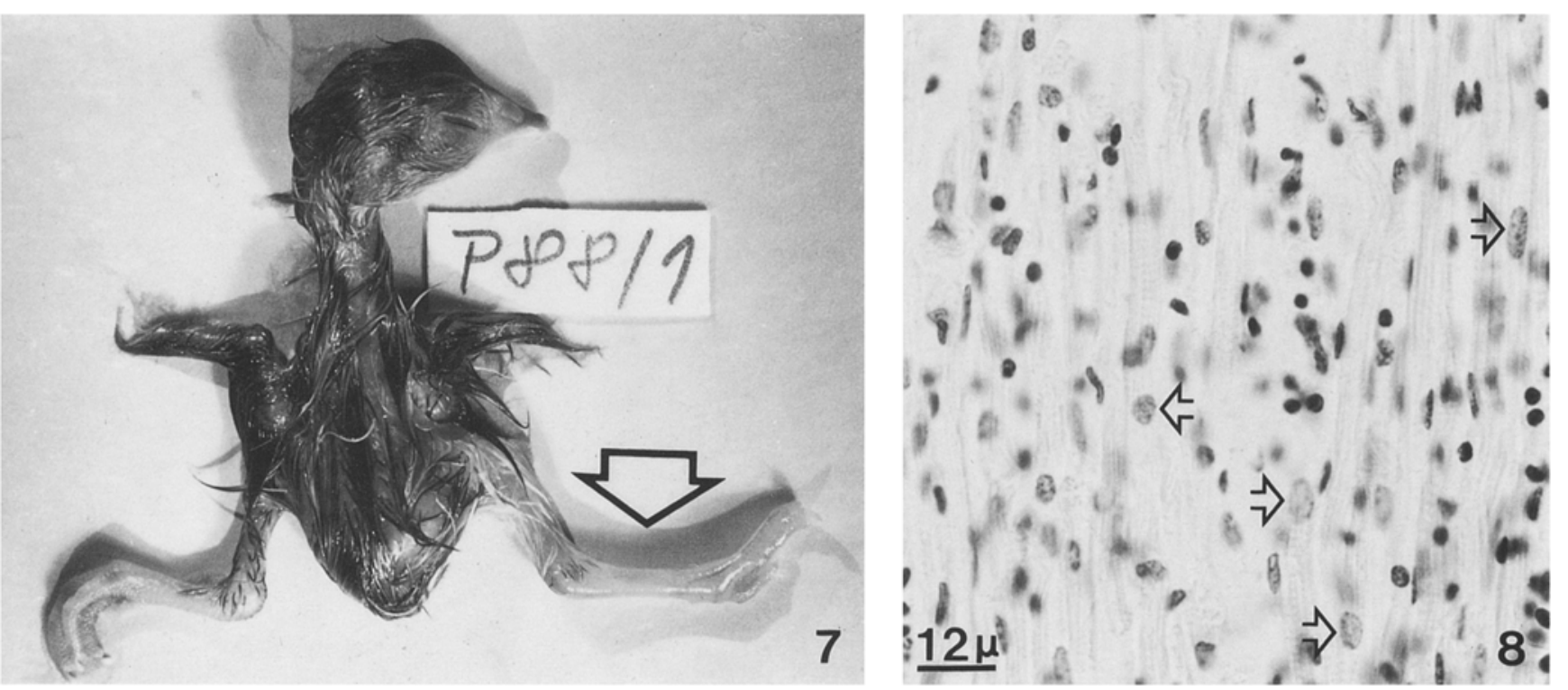

Fig. 7. Quail host after grafting a chick leg (arrow) in place of the right quail leg and a subsequent reincubation period of 13 days

Fig. 8. Medial gastrocnemius muscle cut out from a grafted leg. Note the chick nuclei within the myotubes (arrows)

According to the findings mentioned above, motoneurons of the host embryo must have dictated the innervation pattern of the PL.

III. PL innervated by inappropriate motoneurons

In the third experimental series leg buds were grafted in place of wing buds using the quail-chick system. Figure 10 shows a quail leg grown instead of the right wing of a chick host. Before fixation it had been noticed that the transplanted leg moved synchronously with the opposite wing. Only those legs have been evaluated, that were found to exhibit a normal shape as well as normal skeletal and muscular pattern. Histological examinations were performed in this series, too (not shown). 

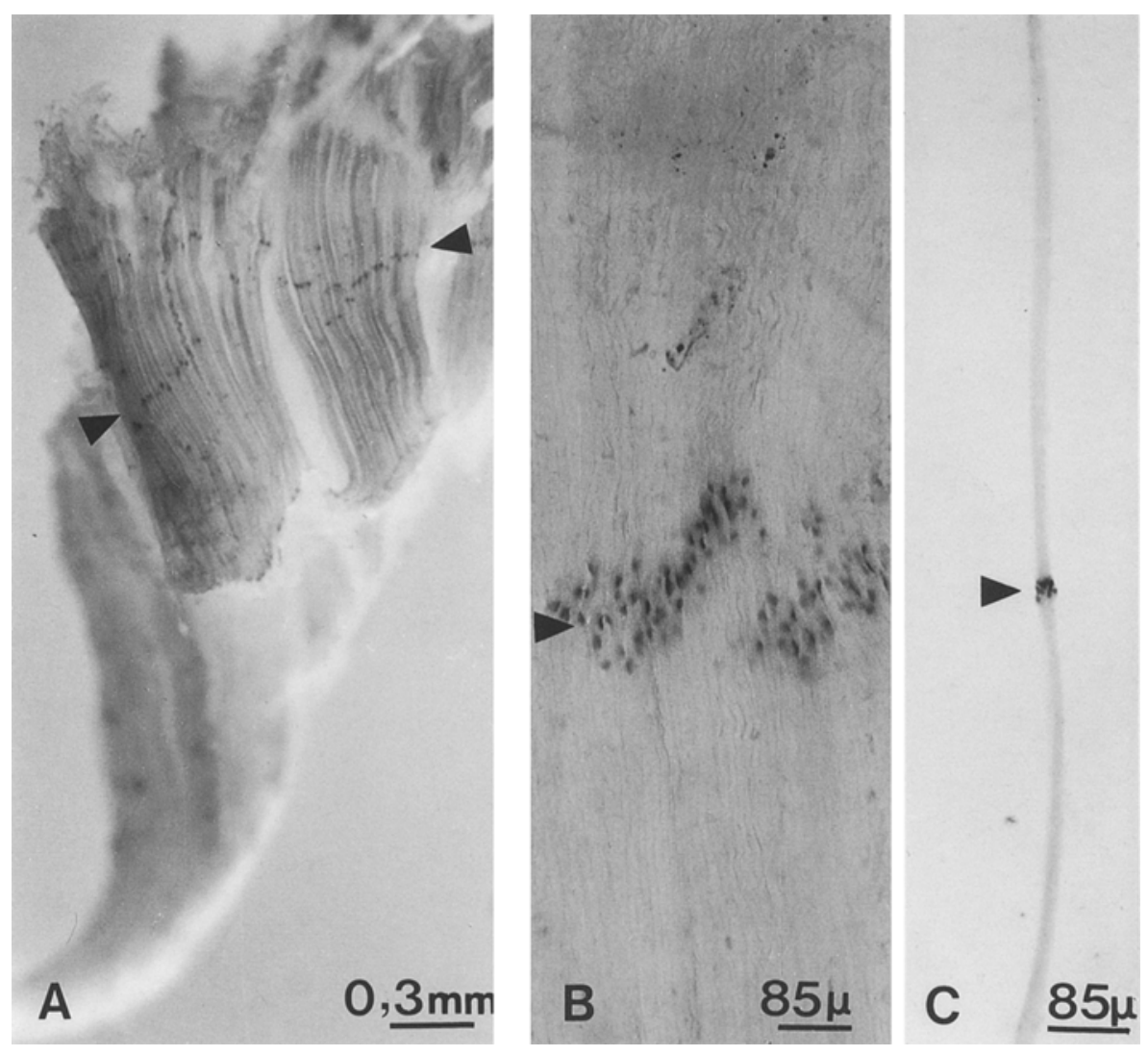

Fig. 9A, B. Quail-like endplate pattern of and chick PL in a chick leg grown in place of the quail leg.

A Dorsal surface of the whole muscle. B Higher magnification of the dorsal part of the PL.

C Small muscle fibre bundle. Arrows: endplates
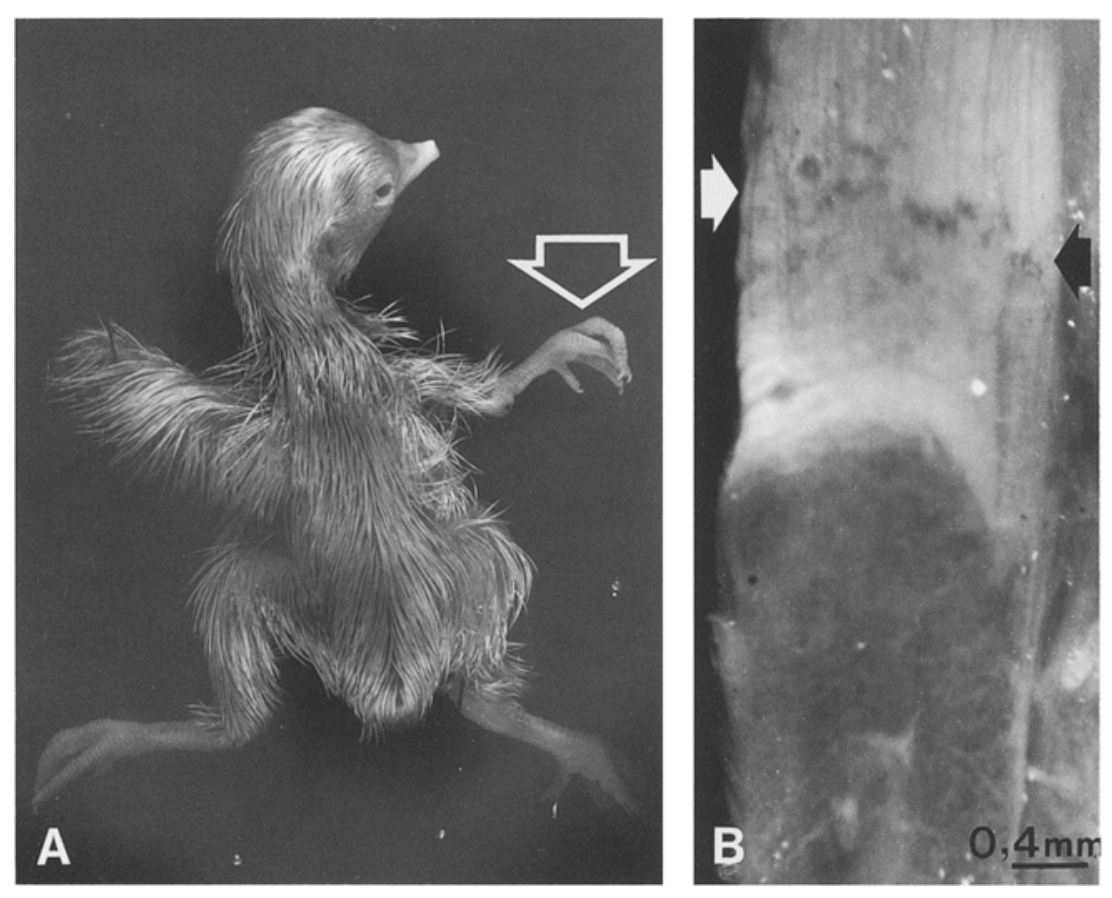

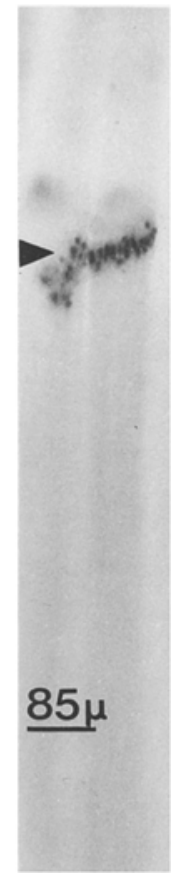

Fig. 10. A Chick host with a quail leg (arrow) grown in place of the right wing.

B Dorsal surface of the PL muscle showing a quail-like endplate pattern (arrows).

C Bundle of muscle fibres. Arrow: endplates
Figure 10 shows the endplate pattern of a PL cut out of a quail leg and innervated by inappropriate motoneurons located in the brachial part of the spinal cord. The most interesting observation that emerged from this series is that an endplate pattern characteristic of the donor PL has developed. That is to say, that inappropriate motoneurons do not have the ability to determine the motor innervation type of the muscle.

\section{Myosin ATPase reaction}

According to the classification of Barnard et al. (1982), the PL of the chick is composed of two subclasses of type IIIfibres which are multiply innervated (Fig. 11). Fibres which are stained in a medium way belong to the type III $A$ and those which are intensely stained to type III B. The quail PL shows weakly stained (acid-sensitive) type II-fibres 

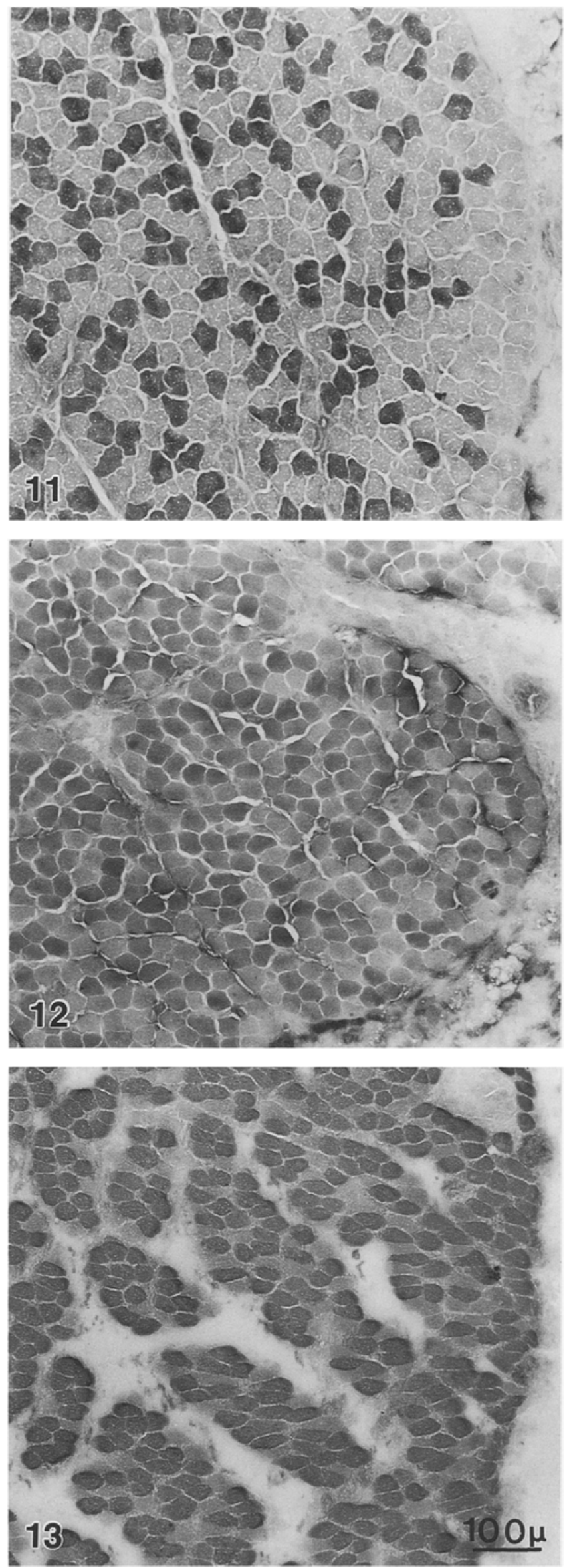

which are focally innervated (Fig. 12). They are especially numerous on the dorsal surface of the muscle. The darkly stained (acid-stable) fibres are multiply innervated and represent III A in III B types. In chimeras in which the PL of quail origin is innervated by appropriate chick motoneurons, muscle fibres can be found which are stained darkly and in a medium way (Fig. 13). These fibres belong to the III A and III B types which are typical of the chick PL. Weakly stained type II-fibres are rare.

\section{Localization of PL motoneuron pool}

It remains to be checked that in the case of orthotopically grafted legs the PL is actually innervated by appropriate motoneurons. In six chicks to which a quail leg bud had been grafted, the motoneuron pools were made visual using the HRP technique. The PL of grafted quail leg and of the opposite chick leg of E 10 and E 11 hosts were injected with HRP. Labeled motoneurons were examined in transverse serial sections of the spinal cord. In addition, also in E 9 an E 10 quail the motoneuron pool of PL was demonstrated in the same way. In both species the majority of stained motoneurons is found in the lumbosacral segments 4-6 (LS 4-6) (Fig. 14). These motoneurons are grouped in the medial region of the lateral motor column. The position of the PL motoneuron pool of grafted quail legs is in accordance with that found in the contralateral half of the spinal cord with respect to their mediolateral and cranio-caudal extent. It therefore can be stated that the PL of the grafted quail leg innervated by the chick spinal cord received innervation from the appropriate $\mathrm{PL}$ motoneuron pool.

\section{Discussion}

To get a better understanding of mechanisms involved in the control of the development of muscle specific motoneuron innervation, endplate patterns of the PL in legs that had been previously transplanted between chick and quail embryos are studied. Investigations are based on the observation that PL muscles of chick and quail show different endplate patterns and are made up of distinct muscle fibre types (Grim et al. 1985). The chicken PL consists of multiply innervated slow fibres while the quail PL is mainly composed of focally innervated fast fibres. The experimental design thus far provides the possibility to force appropriate or inappropriate motoneurons of one species to innervate the PL of the other species.

The terms "appropriate" and "native" are used to characterize motoneurons located within the pool from

Fig. 11. Fibre type composition of the dorsal part of the quail PL. Myosin ATPase reaction. Focally innervated type II fibres are weakly stained; multiply innervated type III A and III B fibres are darkly stained

Fig. 12. Fibre type composition of the dorsal part of the chick PL. Myosin ATPase reaction. Muscle is made up of multiply innervated type III $A$ and III $B$ muscle fibres

Fig. 13. Chimeric quail PL innervated by appropriate chick motoneurons. Muscle fibres belong tho the III A and III B types which are typical of the chick PL 

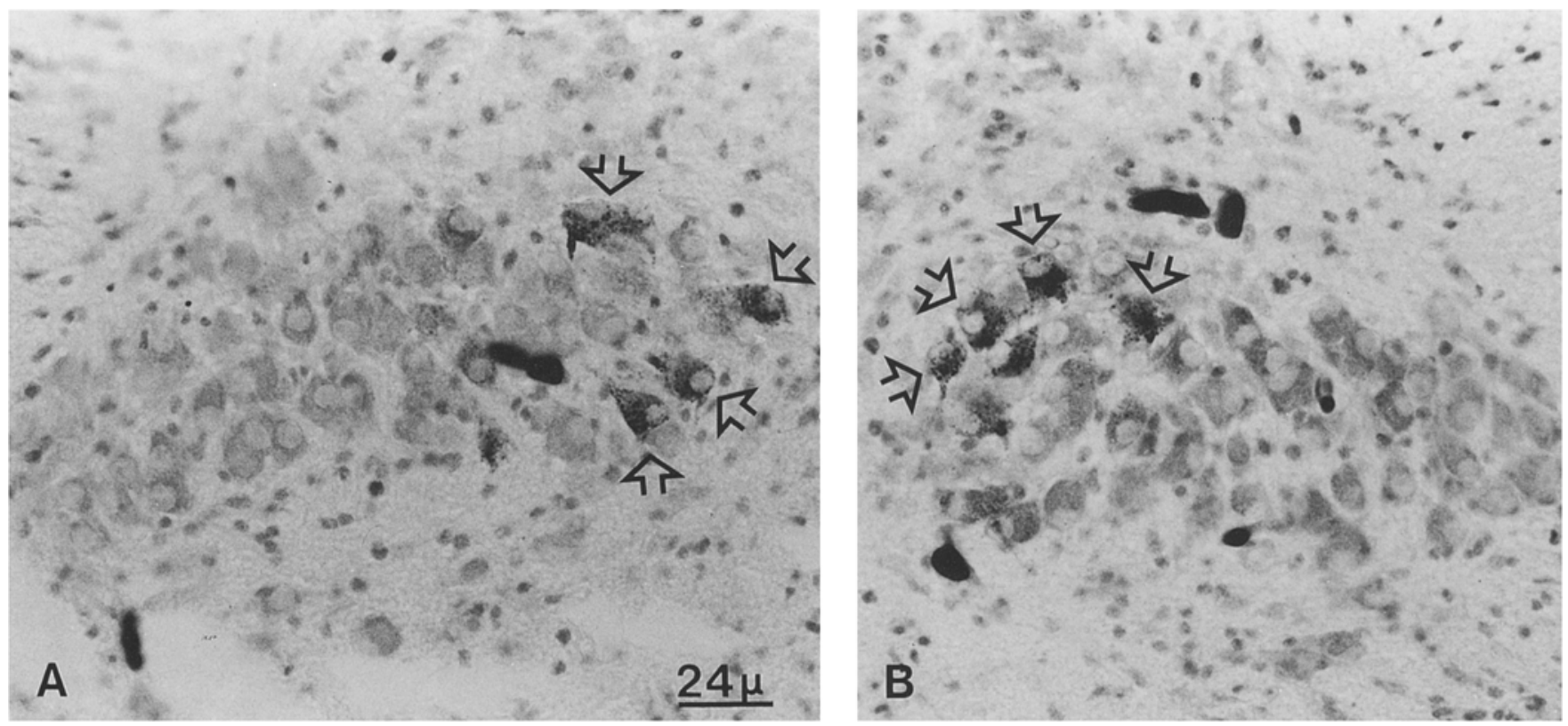

Fig. 14A, B. Cross section through lateral motor columns (LMC) at the LS level after HPR injecting into PL muscles. Arrows: motoneurons of PL pools closely clustered in a discrete medial region of the LMC contain granular reaction product. Cresyl violet staining. A Pool of PL motoneurons of the normal left chick leg. B Motoneuron pool of the PL within the grafted quail leg of the right side

which the PL is normally innervated regardless of the species. "Foreign" or "inappropriate" motoneurons are those located within spinal cord segments which normally do not contribute to the leg innervation. The effect of the experimentally altered motor innervation is analyzed by staining the endplates. The evaluation of the experimental series yield the following results.

1. PL muscles within quail legs orthotopically transplanted to chick hosts develop an endplate pattern characteristic of the chick.

2. PL muscles within chick legs orthotopically transplanted to quail hosts develop an endplate pattern characteristic of the quail.

3. PL muscles within legs heterotopically transplanted develop an endplate pattern characteristic of the donor embryo.

4. PL muscles within transplanted legs are always found to be mainly made up of donor myocytes.

5. The myosin ATPase reaction shows that appropriate motoneurons are able to alter the fibre type.

6 . The location of the motoneuron pool innervating the PL within grafted quail legs corresponds to the location of the motoneuron pool innervating the normal chick PL.

Thus, our results show that appropriate motoneurons in avian chimeras are able to dictate a muscle innervation type that normally does not occur. Unlike this dictatorial influence of appropriate motoneurons inappropriate motoneurons do not determine the endplate pattern of the muscle. In this case the endplate pattern corresponds to that found in the normal leg. From these results it can be deduced that at least two different influences controlling endplate pattern formation can become effective, a central and a peripheral one.

Our findings concerning the dictatorial influence of motoneurons on development of focally or multiply innervated muscle fibres are in line with the cross-innervation experiments performed by Hnik et al. (1967), Jirmanová et al.
(1971)) and Jirmanová and Zelená (1973) who transplanted the nerves between the multiply innervated ALD and the focally innervated PLD using adult and especially young chicken. Under these experimental conditions, a focal innervation develops in the ALD and a multiple one in the PLD. Recently, Vogel and Landmann (1987) got some evidence that under exceptional circumstances after a motoneuronmuscle fibre type mismatch, embryonic motoneurons can alter fibre type expression.

Various observations exist that point to an involvement of muscle primordia itselves in determining the fibre types and endplate pattern during embryonic development. Christ et al. (1983) showed that after replacement of the brachial neural tube by leg level neural tube in the avian embryo, the UMD of the wing does not change its normal motor innervation pattern. This muscle is characterized by a multiply innervation dorsal and a focally innervated ventral part (Grim et al. 1983). Similar results were obtained after grafting the wing bud in place of the leg bud (Jacob et al. 1983; Laing and Lamb 1983; Grim et al. 1986). In all cases the inappropriately innervated UMD exhibits a normal, that is to say an unchanged endplate pattern. Moreover, despite the foreign innervation the subsequent development of the distribution of fast and slow muscle fibres, as judged by ATPase staining, was normal in all muscles examined (Laing and Lamb 1983). Butler et al. (1986) maintained that "naive nerves lacked the memory of a previous partner" and thus, cannot alter fibre types if they are forced to innervate inappropriate muscles. Studying aneurogenic limbs, Christ et al. (1979) found a normal muscle pattern. Examining such muscles by means of myosin ATPase histochemistry, Butler et al. (1982) observed that in those muscles, lacking any peripheral neuronal influences, the initial differentiation of distinct fibre types does occur.

If we favour the model of intrinsic fibre type differentiation, the question arises how the myotubes become determined. Studies concerning limb muscle development have 
shown clearly that the myoblasts originate from the somites while the total of the muscular connective tissue derives from the somatopleure (Christ et al. 1974, 1977; Chevallier et al. 1976, 1977). The somite-derived myoblasts were found to be "naive" with respect to their destination within the limb (Chevallier et al. 1977; Christ et al. 1978; Lance-Jones $1988 \mathrm{a}, \mathrm{b})$. After heterotopical substitution of brachial somites in a chick host by non-brachial quail somites, the chimeras show a normally developed chick-specific muscle pattern and the muscles are made up of quail myocytes (Jacob et al. 1983). Development of individual muscle form is brought about by influences mediated by the somatopleure-derived connective tissue of the limb (Jacob and Christ 1980). Such chimeric wings also show a normal endplate pattern. It is therefore suggested that the developing myotubes become informed of their spatial arrangement and of their fibre types by local cues mediated by cell-cell or cell-matrix interactions (Christ et al. 1986). This has been recently supported by Butler et al. (1988).

Looking at the results mentioned above, it can be suggested that the motoneurons determine the muscle fibre types. On the other hand, the significance of peripheral influences for the muscle specific endplate pattern formation is experimentally well documented. The results on the PL obtained with quail-chick chimeras offer a possibility to get out of this controversial issue. We set out a model proposing a hierarchy of factors controlling motoneuron innervation.

If appropriate motoneurons are allowed to project to the PL, that species-specific endplate pattern is expressed which is inherent in the motoneuron pool. In this case, the centrally situated information wins through against the peripherally located programme. During normal development of motoneuron innervation the centrally and peripherally located programmes are identical, what might be the reason for the generation of the high neuromuscular specificty.

If inappropriate motoneurons are forced to project to the PL, the species-specific pattern is realized that is inherent in the muscle primordium itself. In the latter case, the peripherally located information wins through against the central one, on condition that muscle fibres are in the position to choose appropriate partners. In the vast majority of experiments such connections seem to be set up. Under these circumstances which do not exist during normal development axons may compete with each other (for review: Bennett 1983). According to the statement made by Vrbová et al. (1978) there "is a clear preference of slow nerve fibres for slow muscle fibres and fast nerve fibres for fast muscle fibres". Muscle cells differentiated within the limbs are supposed to possess identities, detectable by differences in myosin ATPase content, before they are innervated (Bennett 1983). If under experimental conditions, the number of corresponding motoneurons is not sufficient, it may happen that muscle fibres are forced to accept a wrong partner. This might explain the motoneuron-muscle fibre type mismatch leading to an alteration of fibre type expression in some muscles as was observed by Vogel and Landmesser (1987) and several other authors who performed cross-innervation experiments in young chickens and points to a plasticity of muscle fibres to some extent under the influence of a separate axon information.

According to Landmesser (1978) and Hollyday (1980) motoneurons exhibit target selectivity. If inappropriate motoneurons mismatch a foreign muscle their first choice is a muscle fibre of the corresponding type. In case they do not find the right partner second choice innervations will develop. This might be interpreted as an expression of a hierarchy of neuronal specifities (Hollyday et al. 1977).

According to the hierarchy concept given in this paper, firstly muscles innervated by appropriate motoneurons express an endplate pattern which is established within the pool. We therefore cannot support the suggestion of Butler et al. (1986) that motoneurons projecting to muscle primordia are judged to be naive with respect to slow and fast characteristics. If, secondly, the centrally located programme cannot be realized the peripheral programme is found to dominate. That may best explain the stability of the endplate pattern seen in the UMD of heterotopically grown wings (Jacob et al. 1983; Laing and Lamb 1983; Grim et al. 1986). Thus, realization of neuromuscular synapse formation is suggested to be molecularly based on recognition processes between axons of different motoneurons and different muscle cells. One might assume that motoneurons and myogenic cells are uniquely labeled in accord with their axial level of origin early in development (LanceJones $1988 \mathrm{a}, \mathrm{b}$ ). As was mentioned above muscle precursor cells of the somites were found to be blank with respect to their level. However, the possibility exists that the somatopleure which subsequently form the connective tissue and the substrates of the highways are marked by level-specific signals.

Reviews in which HRP techniques are discussed (Hollyday 1980; Landmesser 1980) show that motoneurons laterally situated within the lateral motor column (LMC) project to muscles arising from the dorsal premuscular mass while motoneurons medially situated within the LMC, project to muscles arising from the ventral premuscular mass. The PL as well as the medial part of the gastrocnemius muscle of the chick were found to come from a common muscle primordium which originates from the ventral premuscular mass (Pautou et al. 1982). This must also be true for the quail. Therefore, the species-specific origin of the PL in quail-chick chimeras can be judged by histological examinations of pieces cut out from the medial part of the gastrocnemius muscle.

In accordance with the developmental origin of the PL in both species the motoneuron pool of the PL was found in the medial part of the LMC. Tanaka and Landmesser (1986) showed that in chick-quail chimeras motoneuron pools of one species selectively innervate homologous muscles in the limb of the opposite species with considerable precision. After transplantations of the quail leg bud in place of chick leg bud the motoneurons innervating the quail PL were situated in a position which corresponds to the pool of the normal chick PL. Therefore, it is likely that the PL of the quail became innervated by appropriate motoneurons.

Looking at the results obtained with the PL in quailchick chimeras we feel that the concept of a hierarchical control of motoneuron innervation might help to reconcile the different experimental results and controversial theories dealing with this subject.

Acknowledgements. We would like to thank Mrs. E. Friedrichová, M. Cechová, Prague, Mr. H. Hake, Bochum, Mrs. M. Köhn, Bochum, Mr. M. Med, Prague, Mrs. S.R.M. Tyrrell, Ann Arbor, for expert technical assistance and for the illustrations, and Mrs. B. Scharf, Bochum, for typing the manuscript. 


\section{References}

Barnard EA, Lyles JM, Pizzey JA (1982) Fibre types in chicken skeletal muscles and their changes in muscular dystrophy. J Physiol 331:333-354

Bennett MR, Pettigrew AG (1974) The formation of synapses in reinnervated and cross-reinnervated striated muscle during development. J Physiol 241:547-573

Bennett MR (1983) Development of neuromuscular synapses. Physiol Rev 63:915-1048

Butler J, Cosmos E, Brierley J (1982) Differentiation of muscle fiber types in aneurogenic brachial muscles of the chick embryo. J Exp Zool 224:65 80

Butler J, Cauwenbergs P, Cosmos E (1986) Fate of brachial muscles of the chick embryo innervated by inappropriate nerves: Structural, functional and histochemical analyses. JEEM 95:147-168

Butler J, Cosmos E, Cauwenbergs P (1988) Positional signals: evidence for a possible role in muscle fibre-type patterning of the embryonic avian limb. Development 102:763-772

Chevallier A, Kieny M, Mauger A (1976) Sur l'origine de la musculature de l'aile chez les oiseaux. CR Acad Sci Paris Série D 282:309-311

Chevallier A, Kieny M, Mauger A (1977) Limb-somite relationship: origin of the limb musculature. JEEM 41:245-258

Christ B, Jacob HJ, Jacob M (1974) Über den Ursprung der Flügelmuskulatur. Experimentelle Untersuchungen mit Wachtel- und Hühnerembryonen. Experientia (Basel) 30:1446-1448

Christ B, Jacob HJ, Jacob M (1977) Experimental analysis of the origin of the wing musculature in avian embryo. Anat Embryol 150:171-186

Christ B, Jacob HJ, Jacob M (1978) Zur Frage der regionalen Determination der frühembryonalen Muskelanlagen. Experimentelle Untersuchungen an Wachtel- und Hühnerembryonen. Verh Anat Ges 72:353-357

Christ B, Jacob HJ, Jacob M (1979) Experimentelle Untersuchungen zum Problem der Muskelindividuation in den Extremitäten von Vogelembryonen. Verh Anat Ges 73:537--544

Christ B, Jacob HJ, Seifert R, Grim M, Jacob M (1983) In-vivoMarkierung motorischer Neurone nach Neuralrohrtransplantationen bei Vogelembryonen. Verh Anat Ges 77:473-475

Christ B, Jacob M, Jacob HJ, Brand B, Wachtler F (1986) Myogenesis: A problem of cell distribution and cell interactions. In: Bellairs R, Ede DA, Lash JW (eds) Somites in developing embryos. Plenum Press New York and London (Nato-Series), pp 261-275

Dossel WE (1958) Preparation of tungsten micro-needles for use in embryonic reserarch. Lab Invest 7:171-173

Feulgen R, Rossenbeck H (1924) Mikroskopisch-chemischer Nachweis eine Nucleinsäure vom Typus der Thymonucleinsäure und die darauf bestehende elektrive Färbung von Zellkernen in mikroskopischer Präparatur. Hoppe Seyler's Z Physiol Chem 135:203-252

Ginsborg BL (1960) Some properties of avian skeletal muscle fibres with multiple neuromuscular junctions. J Physiol 154:581-598

Grim M, Christ B, Klepácek J, Vrabcová M (1983) A comparison of motor end-plate distribution and the morphology of some wing muscles of the chick and quail. J Histochem 15:289-291

Grim M, Christ B, Jacob HJ, Vrabcová M (1985) Chick and quail specific pattern of endplates and fibre-types in the plantaris muscle. Physiol Bohemoslov 34:247-249

Grim M, Christ B, Jacob HJ (1986) Über die Entstehung des Muskel- und Endplattenmusters. Experimentelle Untersuchungen an Extremitätenanlagen von Huhn- und Wachtelchimären. Verh Anat Ges 80:127-135

Guth L, Samaha FJ (1970) Procedure for the histochemical demonstration of actomyosin ATPase. Exp Neurol 28:365-367

Hamburger V (1942) A manual of experimental embryology, 1st edn. Univ of Chicago Press, Chicago, Illinois

Hamburger V, Hamilton HL (1951) A series of normal stages in the development of the chick embryo. J Morphol 88:49-92

Hara K (1971) Micro-surgical operation on the chick embryo in ovo without vital staining. A modification of the intra-coelomic grafting technique. Mikroskopie 27:267-270

Hess A (1961) Structural differences of fast and slow extrafinal muscle fibres and their nerve endings in chicken. J Physiol (Lond) 157:221-231

Hollyday M, Hamburger V (1977) An autoradiographic study of the formation of the lateral motor column in the chick embryo. Brain Res 132:197-208

Hollyday M (1980) Motoneuron histogenesis and the development of limb innervation. Curr Top Dev Biol 15:181-215

Holt SJ (1958) Indigogenic methods for esterases. In: Danielli IF (ed) General cytochemical methods, vol 1. Academic Press, New York, pp 375-398

Hnik P, Jirmanová J, Vyklicky L, Zelená J (1967) Fast and slow muscles of the chick after nerve cross-union. J Physiol 193:309-325

Jacob HJ, Christ B (1980) On the formation of muscular pattern in the chick limb. In: Merker HJ, Nau H, Neubert D (eds) Teratology of the limbs. Walter de Gruyter, Berlin New York, pp 89-97

Jacob HJ, Christ B, Grim M (1983) Problems of muscle pattern formation and of neuromuscular relations in avian limb development. In: Kelley RO, Goetinck PF, MacCabe JA (eds) Limb development and regeneration, Part B. Alan R Liss, New York, p $333-341$

Jacob M, Christ B, Jacob HJ (1979) The migration of myogenic cells from the somites into the leg region of avian embryos. An ultrastructural study. Anat Embryol 157:291-309

Jacob HJ, Christ B, Jacob M (1986) Origin and development of avian limb muscles. Acta Histochem [Suppl-Bd] XXXII:145150

Jirmanová I, Zelená J (1973) Ultrastructural transformation of fast chicken muscle fibres induced by nerve cross-union. Z Zellforsch 146:103-121

Jirmanová I, Huik P, Zelená J (1971) Implantation of "fast" nerve into slow muscle in young chickens. Physiol Bohemoslov 20:199-204

Karnovsky MJ, Roots L (1964) A "direct-coloring" thiocholine method for choline esterase. J Histochem Cytochem 12:219-221

Khaskiye A, Toutant J-P, Toutant M, Renaud D, Le Douarin GH (1980) Effect of hetertopic innervation on the development of synaptic pattern in chick embryo muscles. Arch d'Anatomie microsc Tome 69:135-146

Khaskiye A, Renaud D, Le Douarin G (1987) Effects of electrical stimulation upon post-hatching development of fibre types in normally innervated fast and slow latissimus dorsi-muscles of the chicken. Biol Cell $61: 163-170$

Laing NG, Lamb AH (1983a) The distribution of muscle fibre types in chick embryo wings transplanted to the pelvic region is normal. JEEM 78:67-82

Laing NG, Lamb AH (1983 b) Development and motor innervation of a distal pair of fast and slow wing muscles in the chick embryo. JEEM 78:53-66

Lance-Jones C (1988a) The somitic level of origin of embryonic chick hindlimb muscles. Dev Biol 126:394-407

Lance-Jones C (1988 b) The effect of somite manipulation on the development of motoneuron projection patterns in the embryonic chick hindlimb. Dev Biol 126:408-419

Landmesser L, Morris DG (1975) The development of functional innervation in the hind limb of the chick embryo. J Physiol $249: 301-326$

Landmesser L (1978) The distribution of motoneurons supplying chick hind limb muscles. J Physiol 284:371-389

Landmesser L (1980) The generation of neuromuscular specifity. Ann Rev Neurosci 3:279-302

Le Douarin N (1969) Particularités du noyau interphasique chez la caille japonaise (Coturnix coturnix japonica). Utilisation de ces particularités comme "marquage biologique" dans les recherches sur les interactions tissulaires et les migration cellulaires au cours de l'ontogenèse. Bull Biol Fr Belg 103:435-452 
Lojda Z, Gossrau R, Schiebler TH (1979) Enzyme histochemistry. A Laboratory manual. Springer, Berlin Heidelberg New York

Melichna J, Gutmann E, Syrovy J (1974) Developmental changes in contraction properties adenosine-triphosphatase activity muscle fibre pattern of fast and slow chicken musclek. Physiol Bohemoslov 23:511-520

O'Brien RAD, Vrbová G (1980) Nerve-muscle interactions during early development. In: Pette D (ed) Plasticity of muscle. Walter de Gruyter, Berlin New York, pp 271-281

Padykula HA, Herman E (1955) Factors affecting the activity of adenosine triphosphatase and other phosphatases as measured by histochemical techniques. J Histochem Cytochem 3:161-169

Pautou MP, Hedayat J, Kieny M (1982) The pattern of muscle development in the chick leg. Arch Anat Microsc Morphol Exp 71:193-206

Phillips WE, Bennet MR (1984) Differentiation of fiber types in wing muscles during embryonic development: effect of neural tube removal. Dev Biol 106:457-468

Renaud D, Le Douarin GH, Khaskiye A (1978) Spinal cord stimulation in chick embryo: effects on development of the posterior latissimus dorsi muscle and neuromuscular junctions. Exp Neurol 60:189-200
Tanaka H, Landmesser LT (1986) Interspecies selective motoneuron projection patterns in chick-quail chimeras. J Neurosci $6: 2880-2888$

Tosney KW, Landmesser LT (1986) Neurites and growth cones in the chick embryo. Enhanced tissue preservation and viscualization of HRP-labeled subpopulations in serial $25-\mu \mathrm{m}$ plastic sections cut on a rotary microtome. J Histochem Cytochem 34:953-957

Toutant JP, Toautant MN, Renaud D, Le Douarin GH (1979) Enzymatic differentiation of muscle fibre types in embryonic latissimus dorsi of the chick: effects of spinal cord stimulation. Cell Differ 8:375-382

Vogel M, Landmesser L (1987) Distribution of fibre types in embryonic chick limb muscles innervated by foreign motoneurons. Dev Biol 119:481-495

Vrbová G, Gordon T, Jones R (1978) Nerve-muscle interaction. Chapman and Hall, London

Vrbová G, Navarrete R, Lowrie M (1985) Matching of muscle properties and motoneurone firing patterns during early stages of development. J Exp Biol 115:113-123

Accepted January 24, 1989 